\title{
An examination of the effectiveness of health warning labels on smokeless tobacco products in four states in India: findings from the TCP India cohort survey
}

Shannon Gravely ${ }^{1 *} \mathbb{D}$, Geoffrey T. Fong ${ }^{1,2,3}$, Pete Driezen', Steve Xu¹, Anne C. K. Quah¹, Genevieve Sansone, Prakash C. Gupta ${ }^{4}$ and Mangesh S. Pednekar ${ }^{4}$

\begin{abstract}
Background: In 2009, after many delays and changes, India introduced a single pictorial health warning label (HWL) on smokeless tobacco (SLT) packing - a symbolic image of a scorpion covering $40 \%$ of the front surface. In 2011, the scorpion was replaced with 4 graphic images. This paper tested the effectiveness of SLT HWLs in India and whether the 2011 change from symbolic to graphic images increased their effectiveness.

Methods: Data were from a cohort of 4733 adult SLT users (age 15+) of the Tobacco Control Project (TCP) India Survey from 4 states. The surveys included key indicators of health warning effectiveness, including warning salience, and cognitive, emotional, and behavioral responses to the warnings.

Results: The HWL change from symbolic to graphic did not result in significant increases on any of the HWL outcome indicators. A substantial minority of SLT users were unaware that SLT packages contained HWLs (27\% at both waves). Noticing the warnings was also remarkably low at both waves $(\mathrm{W} 1=34.3 \%, \mathrm{~W} 2=28.1 \%)$. These effects carried over to the cognitive and behavioural measures, where among those who noticed HWLs, about one-third reported forgoing SLT at least once because of the HWLs, and fewer than 20\% reported that HWLs made them think about SLT risks or about quitting SLT. Even fewer reported avoiding HWLS (8.1 to 11.6\%). Among those who quit using SLT by postpolicy, awareness that SLT packaging contained HWLs was significantly greater at post-policy (86.8\%) compared to pre-policy $(77.8 \%, p=0.02)$. Quitters were also significantly more aware of the post-policy HWLs compared to those who continued to use SLT $(p<0.001)$.

Conclusions: Health warnings on SLT packages in India are low in effectiveness, and the change from the symbolic warning (pre-policy) to graphic HWLs (post-policy) did not lead to significant increases of effectiveness on any of the HWL indicators among those who continued to use SLT products, thus suggesting that changing an image alone is not enough to have an impact. There is a critical need to implement SLT HWLs in India that are more salient (large in size and on the front and back of the package) and impactful, which following from studies of HWLs on cigarette packaging, would have strong potential to increase awareness of the harms of SLT and to motivate quitting.
\end{abstract}

Keywords: Tobacco control, Health policy, Health warning labels, Smokeless tobacco

\footnotetext{
*Correspondence: shannon.gravely@uwaterloo.ca

'Department of Psychology, University of Waterloo, 200 University Avenue

West, Waterloo, ON N2L 3G1, Canada

Full list of author information is available at the end of the article
}

(c) The Author(s). 2016 Open Access This article is distributed under the terms of the Creative Commons Attribution 4.0 International License (http://creativecommons.org/licenses/by/4.0/), which permits unrestricted use, distribution, and reproduction in any medium, provided you give appropriate credit to the original author(s) and the source, provide a link to the Creative Commons license, and indicate if changes were made. The Creative Commons Public Domain Dedication waiver (http://creativecommons.org/publicdomain/zero/1.0/) applies to the data made available in this article, unless otherwise stated. 


\section{Background}

Over the last decade - since the WHO Framework Convention on Tobacco Control (FCTC) came into force in 2005 - there has been strong progress in tobacco control in many countries around the world. These efforts however have been largely focused on smoked tobacco (mainly manufactured cigarettes) with limited attention paid to other harmful and prevalent tobacco products, such as smokeless tobacco (SLT).

Currently, more than 300 million adults in 70 countries across all WHO regions use SLT, of which 250 million (90\% of global SLT users) are in the 11 countries of the WHO's South East Asian Region (SEAR) [1]. Notably, rural users in India and Bangladesh make up 80\% of the total SLT users in the world [2]. Moreover, studies have shown that SLT use is highest among SEAR's illiterate and low socioeconomic populations [1].

SLT products represent a significant risk to human health [3-6]. There is considerable diversity of SLT products, but those commonly used in the SEAR, and notably in India, include highly toxic forms, with very high levels of harmful constituents such as nitrosamines and heavy metals $[2,7,8]$. SLT products in SEAR have been shown to cause a broad range of diseases and adverse health effects such as various types of cancers, cardiovascular disease, and adverse pregnancy outcomes $[1,2,5,6,9-11]$. The latter is particularly striking, as SLT use is highly prevalent among reproductive age females in SEAR $[11,12]$.

Despite the considerable evidence base linking SLT use with adverse health outcomes, knowledge of the health effects of SLT remains low $[6,13,14]$. Added to this, there are many misconceptions about SLT, including the belief among many that SLT can be used for health purposes, such as cleansing their teeth and to relieve stress and other health ailments. These misconceptions have likely contributed to low rates of quitting among SLT users in many of these countries $[1,15,16]$.

Due to a lack of public awareness and incomplete knowledge about the harmful effects of SLT, there are significant challenges towards effective tobacco control related to SLT use. One of the most effective public health measures to inform the people about the harms of tobacco products is to implement large pictorial health warning labels (HWLs) [17]. Overall, many collective elements, such as the size, position, content, and design of these messages, influence HWL effectiveness [18-20]; however, although there has been a great deal of global research on the effectiveness of tobacco HWLs on manufactured cigarette packages, there is little evidence about the impact of these warnings on SLT packaging $[2,21]$. This is particularly true in the SEAR, but most notably in India where SLT use is highly prevalent, and where it exceeds smoked tobacco among both men and women [2].
Smokeless tobacco and health warning labels in India

About 275 million people currently use tobacco in India. Among all tobacco products, SLT is the predominant form used by men (32.9\%), women (18.4\%), and youth $(9.0 \%)$; it exceeds the prevalence of cigarette smoking [22] and that of other smoked products (e.g., bidis) [16]. Men and women also differ in the types of SLT products that they use, and thus are exposed to many different forms of product packaging, which would likely further reduce the impact of HWL by gender [23].

Although India's 2003 Cigarette and Other Tobacco Products Act called for pictorial warnings on both smoked and smokeless tobacco product packaging, tobacco industry influence led to years of delays and dilutions [22, 24, 25]. When pictorial HWLs were finally introduced in 2009, they were weakened so that they did not meet the WHO FCTC Article 11 Guidelines [26]. From May 2009 to November 2011, SLT packages included a HWL with one symbolic image (that of a scorpion, which is unrelated to cancer) on $40 \%$ of the front of the package. In December 2011, the scorpion image was replaced by 4 graphic images of cancer of the mouth, jaw, or neck [27]. In 2013, 3 new graphic HWLs were implemented. All SLT warnings since 2011 were accompanied by the text "TOBACCO KILLS"; however, the size (40\%), location (on the front only), and the lack of rotation remained [22, 25]. The tobacco industry could also freely choose only one of the available warnings [28], http://www.tobaccolabels.ca/countries/india/.

Cross-sectional and qualitative studies show that the 2009 scorpion HWL was poorly understood [29-31], but to our knowledge, there are no longitudinal population studies that have examined the effectiveness of the change from the 2009 scorpion warning to the graphic 2011 HWLs. Therefore the objectives of this paper were to test: (1) the effectiveness of the 2009 and 2011 SLT HWLs in India; and (2) whether the 2011 change from symbolic to graphic images increased effectiveness among validated HWL indicators and intentions to quit SLT use. We conducted this evaluation with a longitudinal cohort design, which confers considerable advantages in policy evaluation [32].

\section{Methods}

\section{Sample design and procedure}

This study is part of the larger TCP India Survey, which is a prospective cohort study of adult (aged $\geq 15$ years) tobacco users and non-users from 4 states in India: Bihar, West Bengal, Madhya Pradesh, and Maharashtra. In each state, residents of the following urban cities and their surrounding rural districts were surveyed: Patna (Bihar), Kolkata (West Bengal), Indore (Madhya Pradesh), and Mumbai (Maharashtra). Within each state, one major city was selected to represent an urban 
area and the surrounding area within a $50 \mathrm{~km}$ diameter outside of the major city was selected to represent a rural area.

At Wave 1, the TCP India Survey followed a stratified multistage cluster sampling design. In order to adjust for potential disproportionate selection of adult tobacco users and non-users in subgroups, enumeration and survey weights were calculated for each enumerated household and survey respondent. Means and proportions reported here were estimated using longitudinal sampling weights that adjust for respondent attrition and are interpreted as the number of people in the population that a respondent represents. Wave 1 of the TCP India Survey was conducted between August 2010 and October 2011, and Wave 2 was conducted between October 2012 and September 2013. Further details about household enumeration in the four states, the study sampling design, the construction of sampling weights, the selection criteria for survey respondents in each household, and the response rates are provided in the TCP India Technical Reports [33].

Fieldwork was conducted by the Healis-Sekhsaria Institute for Public Health in Maharashtra; the School of Preventative Oncology in Bihar; the Madhya Pradesh Voluntary Health Association (MPVHA) in Madhya Pradesh; and the Cancer Foundation of India in West Bengal. Healis led the conduct of the survey in all four states. For the Wave 1 and 2 Surveys, the protocol and questionnaires were first developed in English and then translated into the dominant languages spoken in each state. Respondents answered the survey in their preferred language: English or in Hindi in Bihar and Madhya Pradesh, Marathi in Maharashtra, and Bengali in West Bengal. The average length of the survey interview was $96 \mathrm{~min}$ at Wave 1 and $101 \mathrm{~min}$ at Wave 2. At the end of the interview, respondents were debriefed, remunerated, and thanked for their time. A token of appreciation was presented to each respondent which was a gift equivalent to \$3.00 USD (further details are described in the TCP technical reports) [33]. Ethics clearance was granted by the University of Waterloo, Office of Research Ethics and the HealisSekhsaria Institute for Public Health Institutional Review Board.

\section{Study sample}

Data for this study were drawn from the larger TCP India Survey and included current SLT users that participated at both Wave 1 and Wave 2. A SLT user was defined as use of any smokeless tobacco products at least once a month. The demographic and SLT characteristics of the sample for Waves 1 and 2 are shown in Table 1.

\section{Measures}

\section{Smokeless tobacco users}

All respondents were asked the following question at both Waves 1 and 2: 'Do you currently use any of the following smokeless tobacco products at least once a month' (yes/no/don't know). Those who responded 'yes' at both waves were included as a "SLT user" for the current study. Respondents also identified what type of SLT products that they use. SLT products included (1) those for chewing or holding in the mouth: plain chewing tobacco, slaked lime mixed with tobacco, known as khaini; scented chewing tobacco, known as zarda; (2) areca nut and tobacco mixtures for chewing: gutka, industrially made crushed areca nut with tobacco; betel quid, which is areca nut, tobacco and condiments wrapped in a fresh betel leaf, prepared by vendors or at home; and (3) products used as dentifrices or for application to teeth and gums: dry snuff (also called bajjar or tapkheer), gudhaku (a paste of tobacco and molasses) tobacco toothpaste, pyrolized products (gul and mishri), Lal dantmanjan (red toothpowder).

\section{Demographics and tobacco related variables}

Sociodemographic characteristics were assessed with standard questions on sex, age, marital status, highest educational attainment, and monthly household income (equivalent to US dollar, 1 Indian Rupee (INR) decreased from 0.23 to 0.15 US dollars during the study period). Income and education were categorized as low, moderate, and high. Monthly household income was categorized as "low" (5000 INR or less), "moderate" (5001-15,000 INR), and "high" (15,001 INR or higher). Those who were illiterate, literate with no formal education, completed up to primary school, or middle school were categorized as "low education". Those who completed secondary school were categorized as "moderate education" and those who completed graduate, post-graduate or professional degree or above were categorized as "high education".

Tobacco-relevant variables consisted of: SLT use frequency (On average, how often do you use this product (your most frequent smokeless product: Less than once a week, Once a week, Twice a week, 3-5 times a week, Every day or almost every day, More than once a day), dependence (analogous to the heaviness of smoking index, in this case, the sum of the categorical measures of the daily amount of smokeless used $(0=\leq 10 /$ day, $1=11-20 /$ day, $2=21-30 /$ day and $3=31+/$ day) and the time to first use $(0=>60$ min after waking, $1=31-60$ min after waking, $2=6$ to 30 min after waking and $3=$ within 5 min after waking). The dependence scale therefore took on values from 0 to 6), previous cessation attempts (Have you ever made a serious attempt to stop using all smokeless tobacco products and Have you made a serious attempt to 
Table 1 Respondent's baseline demographic characteristics and smokeless tobacco use behaviours

\begin{tabular}{|c|c|c|c|c|c|c|}
\hline \multirow[t]{2}{*}{ Characteristic, n (\%) } & Maharashtra & Bihar & Madhya Pradesh & West Bengal & Total Sample* & \multirow[t]{2}{*}{$P$-Value } \\
\hline & $n=1101(23.3 \%)$ & $n=1551(32.8 \%)$ & $n=1168(24.7 \%)$ & $n=931(19.3 \%)$ & $N=4733$ & \\
\hline \multicolumn{7}{|l|}{ Sex, $n(\%)$} \\
\hline Male & $514(46.7)$ & $887(57.2)$ & 839 (71.8) & $426(46.7)$ & $2666(56.3)$ & \multirow[t]{2}{*}{$<0.001$} \\
\hline Female & $587(53.3)$ & $664(42.8)$ & $329(28.2)$ & $487(53.3)$ & 2067 (43.7) & \\
\hline \multicolumn{7}{|l|}{ Age, $n(\%)$} \\
\hline $15-17$ & $4(0.4)$ & $98(6.3)$ & $22(1.9)$ & $9(1.0)$ & $133(2.8)$ & \multirow[t]{5}{*}{$<0.001$} \\
\hline $18-24$ & $46(4.2)$ & $258(16.6)$ & $140(12.0)$ & $87(9.5)$ & $531(11.2)$ & \\
\hline $25-39$ & $351(31.9)$ & $536(34.6)$ & $379(32.4)$ & $281(30.8)$ & $1547(32.7)$ & \\
\hline $40-54$ & $382(34.7)$ & $388(25.0)$ & $335(28.7)$ & $305(33.4)$ & $1410(29.8)$ & \\
\hline $55+$ & 318 (28.9) & $271(17.5)$ & $292(25.0)$ & $231(25.3)$ & $1112(23.5)$ & \\
\hline \multicolumn{7}{|l|}{ Marital status, n (\%) } \\
\hline Married & $831(75.5)$ & $1111(71.6)$ & $832(71.5)$ & $663(72.9)$ & 3437 (72.7) & \multirow[t]{3}{*}{$<0.001$} \\
\hline Single & $74(6.7)$ & 344 (22.2) & $179(15.4)$ & $103(11.3)$ & $558(12.4)$ & \\
\hline Other & $196(17.8)$ & $96(6.2)$ & $152(13.1)$ & $144(15.8)$ & 700 (14.8) & \\
\hline \multicolumn{7}{|l|}{ Education level, $n$ (\%) } \\
\hline Low & $665(60.5)$ & $845(54.5)$ & 739 (63.3) & 718 (79.0) & $2967(62.8)$ & \multirow[t]{3}{*}{$<0.001$} \\
\hline Moderate & $408(37.1)$ & $446(28.8)$ & $336(28.8)$ & $140(15.4)$ & $1330(28.1)$ & \\
\hline High & $27(2.5)$ & $260(16.8)$ & $92(7.9)$ & $51(5.6)$ & $430(9.1)$ & \\
\hline \multicolumn{7}{|l|}{ Income level, $n$ (\%) } \\
\hline Low & $112(10.2)$ & $454(29.3)$ & $348(29.8)$ & $420(46.0)$ & $1334(28.2)$ & \multirow[t]{4}{*}{$<.001$} \\
\hline Moderate & $777(70.6)$ & $834(53.8)$ & $687(58.8)$ & $381(41.7)$ & $2679(56.6)$ & \\
\hline High & $172(15.6)$ & $236(15.2)$ & $89(7.6)$ & $92(10.1)$ & $589(12.4)$ & \\
\hline Not stated & $40(3.6)$ & $27(1.7)$ & $44(3.8)$ & $20(2.2)$ & $131(2.8)$ & \\
\hline \multicolumn{7}{|l|}{ District type, $n(\%)$} \\
\hline Urban & $743(67.5)$ & $1127(72.7)$ & $892(76.4)$ & $691(75.7)$ & $3453(73.0)$ & \multirow[t]{2}{*}{0.75} \\
\hline Rural & $358(32.5)$ & $424(27.3)$ & $276(23.6)$ & $222(24.3)$ & $1280(27.0)$ & \\
\hline \multicolumn{7}{|c|}{ Number of SLT products used, $n(\%)$} \\
\hline 1 & $839(76.2)$ & $1224(78.9)$ & $773(66.2)$ & $673(73.7)$ & $3509(74.2)$ & \multirow[t]{3}{*}{0.039} \\
\hline 2 & $210(19.1)$ & $254(16.4)$ & $302(25.9)$ & $193(21.1)$ & $959(20.3)$ & \\
\hline 3 & $52(4.7)$ & $73(4.7)$ & $92(7.9)$ & $47(5.1)$ & $264(5.6)$ & \\
\hline \multicolumn{7}{|l|}{ Use frequency, $n(\%)$} \\
\hline Less than daily & $7(0.6)$ & $59(3.8)$ & $7(0.6)$ & $20(2.2)$ & $93(2.0)$ & \multirow[t]{3}{*}{$<0.001$} \\
\hline Almost daily & $103(9.4)$ & $565(36.4)$ & $200(17.1)$ & $146(16.0)$ & $1014(21.4)$ & \\
\hline More than once/day & $991(90.0)$ & $927(59.8)$ & $960(82.3)$ & $745(81.8)$ & $3623(76.6)$ & \\
\hline \multicolumn{7}{|c|}{ SLT quit attempt (ever), $n$ (\%) } \\
\hline Yes & $302(27.5)$ & $395(25.6)$ & $304(26.2)$ & $176(19.3)$ & $1177(25.0)$ & \multirow[t]{2}{*}{0.49} \\
\hline No & $798(72.5)$ & $114(74.4)$ & $858(73.8)$ & $734(80.7)$ & $3538(75.0)$ & \\
\hline \multicolumn{7}{|c|}{ Daily SLT consumption (number of times per day) } \\
\hline$\leq 10$ & 1407 (91.5) & $731(81.0)$ & $915(79.4)$ & $1008(91.7)$ & 4061 (86.6) & \multirow[t]{4}{*}{$<0.001$} \\
\hline $11-20$ & $116(7.5)$ & $138(15.3)$ & 205 (17.8) & $74(6.7)$ & $533(11.4)$ & \\
\hline $21-30$ & $10(0.7)$ & $24(2.7)$ & $20(1.7)$ & $12(1.1)$ & $66(1.4)$ & \\
\hline $31+$ & $4(0.3)$ & $9(1.0)$ & $13(1.1)$ & $5(0.5)$ & $31(0.7)$ & \\
\hline
\end{tabular}


Table 1 Respondent's baseline demographic characteristics and smokeless tobacco use behaviours (Continued)

\begin{tabular}{|c|c|c|c|c|c|c|}
\hline \multicolumn{7}{|c|}{ Time to first use after waking (min) } \\
\hline$>60$ & $573(37.1)$ & $338(37.4)$ & $125(10.7)$ & $291(26.5)$ & $1327(28.1)$ & $<0.001$ \\
\hline $31-60$ & $344(22.3)$ & $121(13.4)$ & $291(24.9)$ & $88(8.0)$ & $844(17.9)$ & \\
\hline $6-30$ & $416(26.9)$ & $252(27.9)$ & $572(49.0)$ & $353(32.1)$ & $1593(33.8)$ & \\
\hline$\leq 5$ & $211(13.7)$ & $193(21.3)$ & $180(15.4)$ & $367(33.4)$ & $951(20.2)$ & \\
\hline \multicolumn{7}{|c|}{ SLT quit attempt (in the last year, $n(\%)$} \\
\hline Yes & $116(10.5)$ & $296(19.2)$ & $285(24.6)$ & $117(12.9)$ & $814(17.3)$ & \\
\hline No & 984 (89.5) & 1243 (80.8) & 875 (75.4) & 790 (87.1) & 3892 (82.7) & 0.003 \\
\hline
\end{tabular}

Some characteristics have missing values if they were not reported at time of entry into the study (percentages take into account missing data). Results are unweighted but the survey design was accounted for in the analysis. All tests are the Rao-Scott $X 2$ test unless otherwise indicated

stop using all smokeless tobacco products in the last year (Yes/no), and intentions to quit (Are you planning to quit using smokeless tobacco: Within the next month; Within the next 6 months; Sometime in the future beyond 6 months; Not planning to quit). All questions included an option of "refused" or "don't know".

\section{Health warning effectiveness measures}

Conceptual work and empirical studies have identified key indicators of HWL effectiveness, which have been employed in a wide range of studies across different countries $[19,20,32]$. These key indicators were:

1. Awareness of HWLs on SLT packaging was assessed by asking the question:

"Thinking now about the packages for smokeless tobacco products (paste, sachets, packs, tins, bottles), as far as you know, do any smokeless tobacco packages in India have warning labels?" The response option were: (yes, no, don't know).

2. HWL salience (noticing and reading the warnings closely) was assessed by two questions:

i. "In the last month, how often have you noticed the health warnings on smokeless tobacco packages?" and

ii. "In the last month, how often have you read or looked closely at the health warnings on smokeless tobacco packages?"

The response options for both were: "Never," "Once in a while," "Often," "Very often, and whenever I use smokeless tobacco." These responses were dichotomized into "at least once in a while" vs "Never".

3. Cognitive reactions to the HWLs were: (i) thoughts about the harms of SLT; and (ii) thoughts about quitting and were assessed with the following two questions:

i. "To what extent, if at all, do the warning labels on smokeless tobacco packages make you more likely to think about the health risks (health danger) of using it?" and ii. "To what extent, if at all, do the warning labels on smokeless tobacco packages make you more likely to quit using it?"

The response options were: "Not at all," "A little," and "A lot" and dichotomized into "at least a little" vs "not at all".

4. Behavioral reactions to the HWLs were forgoing SLT use and avoidance of warnings and were assessed by asking:

i. "In the last month, have the warning labels stopped you from using smokeless tobacco when you were about to use it?" Response options were: "Never," "Once," "A couple of times," "Once in a while", and "Many times". This was dichotomized into "at least once" vs "never".

ii. "In the last month, have you made any effort to avoid looking at or thinking about the smokeless tobacco warning labels - such as covering them up, keeping them out of sight, avoiding certain warnings, or any other means?" (Yes/No).

\section{Statistical analyses}

Initial unweighted descriptive statistics were computed for demographic variables and tobacco use characteristics (see Table 1), and weighted estimates were computed for each outcome measure (HWL outcomes and intentions to quit) at each wave.

Binary logistic regression models using generalized estimated equations (GEE) were used to: (1) estimate a weighted, adjusted percentage for each outcome measure pre- and post-policy; and (2) test the difference in pre- and post-policy estimates. All models employed an exchangeable working correlation structure.

The analyses were conducted using SUDAAN (Version 11.0.1), which took into account the multistage sampling design and the longitudinal data. All analyses adjusted for survey wave, state, urban/rural area, sex, age group, marital status, income, education, attempt to quit SLT in the past year, intention to quit SLT, and SLT dependence. The analyses included SLT users that were present both at pre and post-policy and that used SLT 
products only (to reduce bias from dual use of smoked and smokeless products). People who no longer used SLT at the time of the Wave 1 or Wave 2 survey were excluded from the main analyses. Unless otherwise stated, all results were weighted.

Three sub-analyses were conducted to test if: (1) there were differences in types of SLT products used by gender; (2) HWL effectiveness among respondents that reported use of a SLT product with mandated HWLs only (gutkha, chewing tobacco, zadra, snuff and khaini) increased after the 2011 policy change; and (3) HWL awareness and noticeability differed pre-and post-policy among SLT users at pre-policy but had quit by postpolicy (as the cessation survey only included these 2 indicator outcomes), and if quitters were more or less likely to be aware of, or notice the labels by post-policy compared to the respondents that continued to use SLT.

\section{Results}

Pre- and post-policy survey sample differences

The study flow diagram is presented in Fig. 1.

At pre-policy, 5991 respondents reported exclusive use of SLT. At post-policy 668 were lost to attrition and 590 were excluded, leaving 4733 for analyses. Unweighted analyses showed that respondents lost to attrition were more likely to be from Maharashtra $(p<0.001)$, from an urban area $(p<0.001)$, younger $(p<0.01)$, male $(p<0.001)$, did not make an attempt to quit SLT in the last year $(p<0.01)$, and had lower education $(p<0.001)$.

\section{Respondent characteristics}

Overall, $56.3 \%$ of the sample was male, with an average age of 41.8 years \pm 15.8 . The majority of the respondents were married $(72.7 \%)$, of moderate income $(56.6 \%)$, with a low education (62.8\%), lived in an urban area (73.0), and $24.2 \%$ were illiterate. Seventy-four percent of respondents used one type of SLT product, $76.6 \%$ used SLT more than once a day, and $75 \%$ had never tried to quit using SLT.

Figure 2 shows the self-reported use of various SLT products among all respondents, and Additional file 1: Table S1 shows SLT type of products used by respondents using only one product.

When SLT product use was examined by gender, men were significantly more likely to use SLT products with mandated HWLs: gutkha ( $40.2 \%$ vs. $11.9 \%, p<0.001)$, zarda $(10.3 \%$ vs. $7.8 \%, p=0.009)$, chewing tobacco $(26.0 \%$ vs. $13.6 \%, p<0.001)$, and khaini $(32.3 \%$ vs. $2.2 \%, p<0.001)$. Women were more likely to use products without

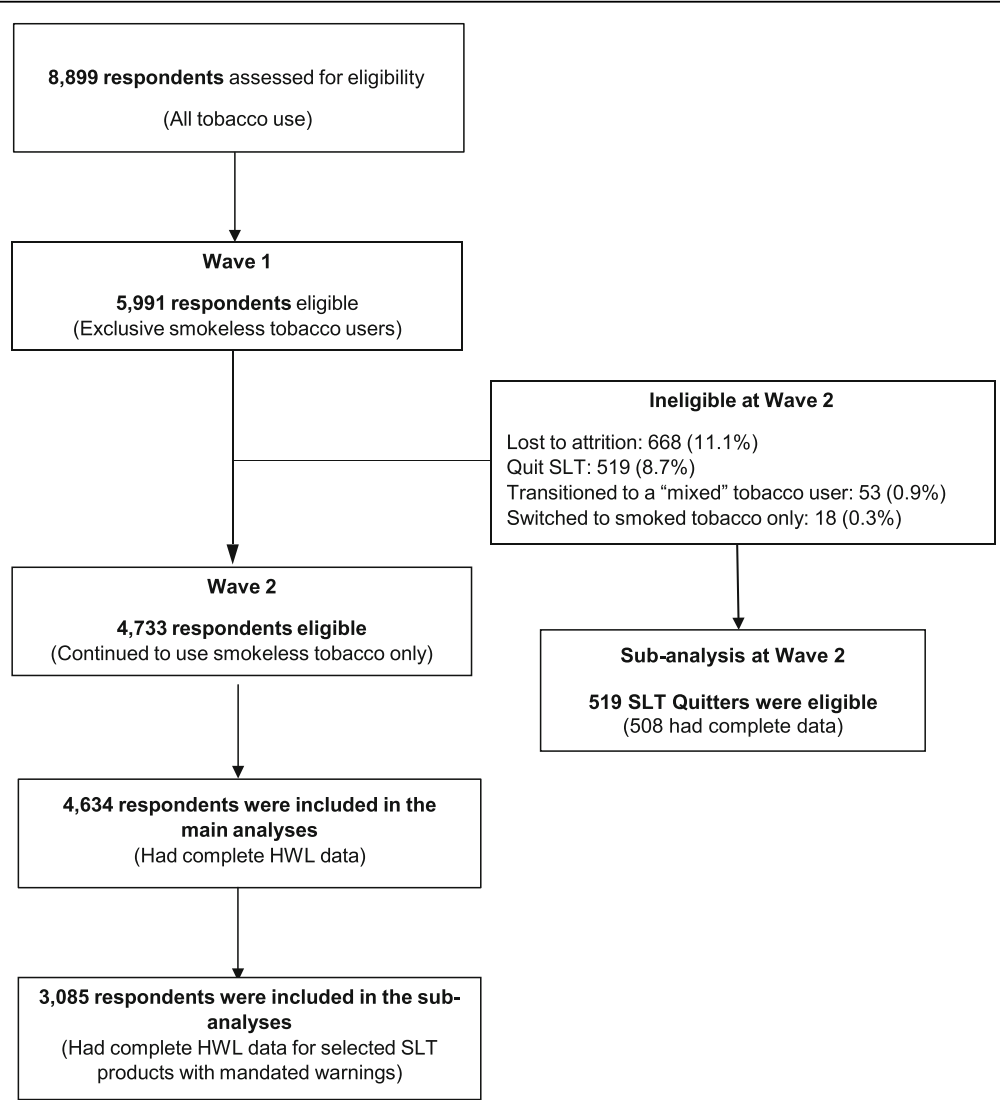

Fig. 1 Study Flow Diagram 


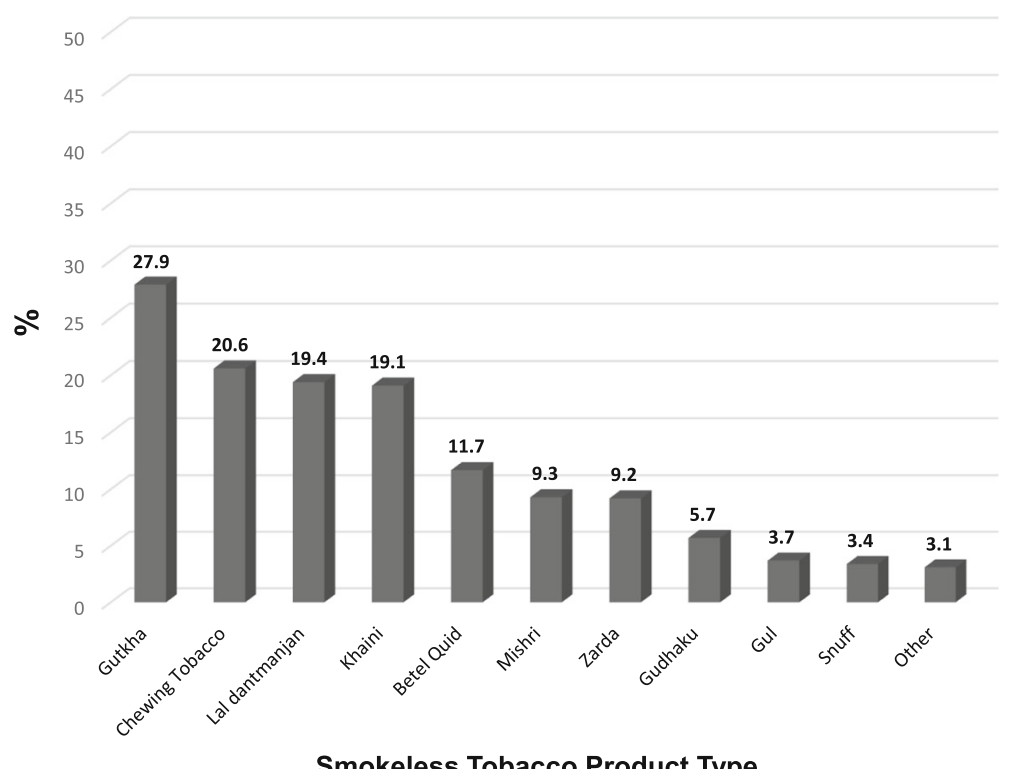

Fig. 2 Types of smokeless tobacco products used among India cohort respondents from all four States. Note that SLT groups are not mutually exclusive (Respondents could have reported more than 1 type)

mandated HWLs: mishri $(17.9 \%$, vs. $2.6 \% p<0.0010$, gudhaku $(11.0 \%$ vs. $1.6 \%, p<0.001)$, Gul $(5.6 \%$ vs. $2.1 \%, p<$ 0.001 ), and lal dantmanjan ( $31.5 \%$ vs. $10.1 \%, p<0.001)$, although women $(6.0 \%)$ were more likely to use snuff compared to men $(1.4 \%, p<0.001)$. There were no sex differences in betel quid use.

\section{SLT User's responses to the HWL changes}

Table 2 presents the results from the GEE adjusted analysis for the $7 \mathrm{HWL}$ indicators, and for quit intentions.
Prior to and after controlling for covariates, the change from symbolic (pre-policy) to graphic (post-policy) HWLs did not lead to significant increases for any of the HWL indicators. There were no differences between pre- $(72.7 \%)$ and post-policy $(73.0 \%)$ user's awareness that SLT packages contained a HWL. Respondents from Bihar and West Bengal, women, older age (those aged 55+), those of lower and moderate education, and SLT users with no intention to quit were significantly less likely than others to respond "yes" to awareness of the HWLs. Additionally, there were no differences

Table 2 GEE analysis examining differences in health warning label impact on smokeless tobacco user's salience, perceptions, behaviour and intensions to quit smokeless between pre- and post-policy periods (Waves 1 and 2)

\begin{tabular}{|c|c|c|c|c|c|c|c|c|c|c|}
\hline \multirow[b]{3}{*}{ Outcome } & \multirow{2}{*}{\multicolumn{3}{|c|}{$\begin{array}{l}\text { Wave } \\
1\end{array}$}} & \multicolumn{7}{|c|}{ Wave } \\
\hline & & & & \multicolumn{3}{|l|}{2} & \multicolumn{4}{|c|}{ Difference between Waves } \\
\hline & $\%$ & $(95 \%$ & $\mathrm{Cl})$ & $\%$ & $(95 \%$ & $\mathrm{Cl})$ & Diff & SE Diff & Test & $p$ value \\
\hline \multicolumn{11}{|l|}{ All respondents $(N=4634)$} \\
\hline Aware that SLT packages contain HWLs (yes) & 72.7 & 67.1 & 77.7 & 73.0 & 67.3 & 78.1 & 0.3 & 2.9 & 0.1 & 0.92 \\
\hline Noticed HWLs at least once in a while (yes) & 34.3 & 28.5 & 40.6 & 28.1 & 21.8 & 35.4 & -6.2 & 4.0 & -1.5 & 0.13 \\
\hline \multicolumn{11}{|l|}{ Among respondents that noticed HWLs $(n=2154)$} \\
\hline Read HWLs at least once in a while (yes) & 49.4 & 42.0 & 56.9 & 50.1 & 40.4 & 59.9 & 0.7 & 6.4 & 0.1 & 0.92 \\
\hline HWLs made you think about risks of SLT at least a little (yes) & 15.0 & 11.9 & 18.8 & 17.5 & 12.1 & 24.6 & 2.5 & 3.1 & 0.8 & 0.42 \\
\hline HWLs made you think about quitting SLT at least a little (yes) & 16.8 & 13.0 & 21.4 & 19.3 & 13.6 & 26.6 & 2.5 & 3.1 & 0.8 & 0.422 \\
\hline Avoided looking at HWLs (yes) & 8.1 & 5.5 & 11.8 & 11.6 & 7.8 & 17.0 & 3.6 & 2.0 & 1.7 & 0.09 \\
\hline Gave up SLT at least once because of HWLs (yes) & 31.3 & 24.3 & 39.3 & 36.7 & 27.2 & 47.5 & 5.4 & 4.9 & 1.1 & 0.27 \\
\hline Any intentions to quit SLT (yes) & 19.8 & 14.6 & 26.4 & 20.5 & 15.2 & 27.0 & 0.6 & 4.5 & 0.1 & 0.89 \\
\hline
\end{tabular}

All estimates are weighted; CI Confidence interval, SLT Smokeless tobacco, HWL Health warning label, SE Standard error, $p$ probability (based on $P<0.05$ ); The data were adjusted with the following covariates: State, sex, urban/rural, age, marital status, income, education, quit attempt in last year, intentions to quit, wave and SLT dependence 
between pre- $(34.3 \%)$, and post-policy $(28.1 \%)$ for noticing the HWLs $(p=0.13)$.

Among respondents who were aware of HWLs, half of the sample reported reading the HWLs at least once in a while $($ pre-policy $=49.4 \%$, post-policy $=50.1 \%, p=0.92$ ), $15.0 \%$ of users at pre-policy and $17.5 \%$ at post-policy reported that HWLs made them think about SLT risks $(p=0.42), 16.8 \%$ at pre-policy and $19.3 \%$ at post-policy reported that HWLs made them think about quitting SLT $(p=0.42)$, and $31.3 \%$ at pre-policy and $36.7 \%$ at post-policy reported giving up SLT at least once because of the HWL $(p=0.27)$. There were low levels of HWL avoidance: $8.1 \%$ of users at pre-policy and $11.6 \%$ at postpolicy $(p=0.09)$. Additionally, there were no changes between pre- (19.8\%) and post-policy (20.5\%) towards greater intentions to quit SLT due to the HWLs $(p=0.89)$. Similarly, when users of SLT products with mandated HWLs only were selected for analysis $(n=3085)$, there remained no significant changes for any of the HWL indicators or intentions to quit (see Table 3).

\section{Quitters' responses to the HWL changes}

There were $519(8.7 \%)$ respondents that self-reported having quit SLT use by post-policy (508 had complete data for analyses). In an adjusted GEE analysis, SLT quitters were added to the main sample so that all respondents that completed a post-policy survey were included $(N=5142)$. Overall, the estimates were similar to the results among the continued users (see Additional file 2: Table S2).

Next, an adjusted GEE that included SLT quitters only, showed that awareness that SLT packaging contained HWLs was significantly greater at post-policy $(86.8 \%)$ compared to pre-policy $(77.8 \%, p=0.02)$.
Quitters were also significantly more aware of the postpolicy HWLs compared to those who continued to use SLT $(p<0.001)$. Noticing the labels at least once in a while between pre- and post-policy was not significant among the SLT quitters, but there was a statistical trend towards a decrease in noticing the HWLs on SLT packaging at post-policy $(p=0.09)$.

\section{Discussion}

Implementing HWLs that meet the FCTC Article 11 Guidelines is an effective strategy for enhancing their perceptual, cognitive, and behavioural impact on tobacco users. However unlike the strong evidence for the effectiveness of HWLs on smoked tobacco packaging $[17,19,20]$, there is little evidence about the effectiveness of HWLs on SLT, and whether enhanced warnings on SLT packaging would impact emotional, cognitive, and behaviour changes among users. This study tested both of these objectives. The results of this first longitudinal study of HWLs on India's SLT products showed that the effectiveness was very low at both pre- and post-policy, and the change from symbolic to graphic images did not increase any of the HWL indicators or intentions to quit SLT, neither among the entire cohort of SLT users nor among those using SLT products with mandated HWLs. Interestingly however, those that quit SLT use were significantly more aware that SLT packaging contained the HWLs at post-policy compared to the pre-policy measure (and quitters were also significantly more aware of HWLs compared to those that continued to use SLT), thus the new graphic HWLs may have impacted those who quit SLT differently that those who continued use. The trend in the decrease of noticing the HWLs among SLT quitters could be explained by the fact that they were no longer regularly exposed to SLT packaging.

Table 3 GEE analysis examining differences in health warning labels on smokeless tobacco user's salience, perceptions, behaviour and intensions to quit smokeless between pre- and post-policy periods (Waves 1 and 2) among those that used SLT with HWL mandated packaging, $n=3085$

\begin{tabular}{|c|c|c|c|c|c|c|c|c|c|}
\hline \multirow[b]{3}{*}{ Outcome } & \multirow{2}{*}{\multicolumn{3}{|c|}{$\begin{array}{l}\text { Wave } \\
1\end{array}$}} & \multicolumn{6}{|c|}{ Wave } \\
\hline & & & & \multicolumn{3}{|l|}{2} & \multicolumn{3}{|c|}{ Difference between Waves } \\
\hline & $\%$ & $(95 \%$ & Cl) & $\%$ & $(95 \%$ & $\mathrm{Cl})$ & Diff & Test & $p$ value \\
\hline Aware that SLT packages contain HWLs (yes) & 78.7 & 72.9 & 83.6 & 80.4 & 75.4 & 84.6 & 1.7 & 0.6 & 0.52 \\
\hline Noticed HWLs at least once in a while (yes) & 38.4 & 31.9 & 45.3 & 31.8 & 25.1 & 39.4 & -6.5 & -1.6 & 0.11 \\
\hline Read HWLs at least once in a while (yes) & 20.8 & 16.4 & 26.1 & 17.5 & 12.8 & 23.5 & -3.3 & -0.9 & 0.35 \\
\hline HWLs made you think about risks of SLT at least a little (yes) & 9.6 & 7.3 & 12.4 & 10.0 & 6.6 & 14.8 & 0.5 & 0.2 & 0.86 \\
\hline HWLs made you think about quitting SLT at least a little (yes) & 9.5 & 6.8 & 13.0 & 11.3 & 7.7 & 16.2 & 1.8 & 0.7 & 0.52 \\
\hline Avoided looking at HWLs (yes) & 4.5 & 3.1 & 6.5 & 5.4 & 3.7 & 8.0 & 0.9 & 0.8 & 0.45 \\
\hline Gave up SLT at least once because of HWLs (yes) & 17.6 & 13.9 & 22.1 & 22.0 & 16.2 & 29.1 & 4.4 & 1.3 & 0.19 \\
\hline Any intentions to quit SLT (yes) & 14.2 & 10.4 & 19.1 & 12.4 & 9.2 & 16.6 & -1.8 & -0.7 & 0.511 \\
\hline
\end{tabular}

All estimates are weighted; $C I$ Confidence interval, SLT Smokeless tobacco, HWL Health warning label, SE Standard error, $p$ probability (based on $P<0.05$ ); The data were adjusted with the following covariates: State, sex, urban/rural, age, marital status, income, education, quit attempt in last year, intentions to quit, wave and SLT dependence 
Among continued SLT users, the low level of effectiveness of the HWLs was evident across the indicators: from awareness and salience to the cognitive and behavioural reactions. Indeed, a substantial minority were not even aware that there were HWLs on SLT products (27\% reported that they were not aware of the 2009 scorpion image or the 2011 graphic images), which is surprising considering that $90 \%$ of the users reported using SLT more than once a day, thus they should have been frequently exposed to the HWLs on SLT packaging. Even when the analyses only included users of SLT products that required mandated HWLs, $20 \%$ reported that they were unaware that the package contained health warnings at both pre-and post-policy. This surprising level of unawareness is similar to that found in smaller cross-sectional studies, including 27.5\% in Karnataka [31], 20\% in the Kumaon Hills of India [34], and 31.2\% in Mumbai [30].

The results from this study confirm those of other studies in India in which HWLs have low levels of noticing and effectiveness $[14,30,31,34]$. There are a number of possible reasons for this low level of effectiveness. For example, SLT packages tend to be considerably smaller in size compared to smoked tobacco products such as cigarettes. As a result, the overall salience will be diminished because of the actual size of the warnings. This is particularly true for single-use packages, which are common. Added to the reduced size, a large proportion of users are poorly educated, which would reduce the comprehension of the warnings. Additionally, there is wide variety and diversity of package design used by SLT manufacturers [2], which is a reflection of their use of packaging as a marketing venue to reinforce brand imagery, to minimize perceptions of risk, and to suggest incorrectly that some types of products are less harmful than others. SLT packaging designs can effectively counteract warning content through creative techniques that can undermine the salience and impact of the warnings (see Fig. 3). Because SLT packages are exceptionally vibrant (e.g., multicolored with elaborate graphic designs), HWLs have to compete for attention. Therefore research is needed to examine the HWL design that will have the

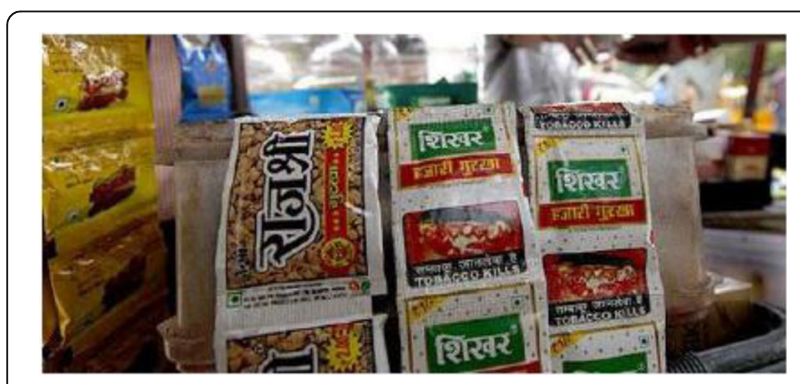

Fig. 3 Example of smokeless tobacco packaging in India f4:2 (December 2011 - April 2016) greatest impact and noticeability on SLT users in India (e.g., they should be much bigger and have contrasting colours to the other packaging design elements) Other reasons for low salience include the fact that some products are made at home, some users may only use SLT in the form of loose tobacco purchased from local farmers or producers (even locally produced and marketed tobacco products with packaging often fail to display HWLs), and many forms of SLT are prohibited from containing tobacco, but often do, thus they do not require a mandated warning (e.g., lal dantmanjan) $[35,36]$.

The weakness of the SLT warnings was also found in the cognitive and behavioral HWL indicators. For example, $10 \%$ of SLT users with mandated HWL packaging reported that the warnings had generated thoughts of quitting, or about the risks of SLT (so this leaves $90 \%$ of users not considering the health risks or quitting SLT use). Furthermore, only $20 \%$ at both pre-and post-policy had intentions to quit SLT use. Similarly, the study by Mutti et al. [37] reported that Indian SLT users intending to quit SLT rated warnings as more effective than those without any quit intentions [37]. ITC findings demonstrate that India's HWLs on smoked tobacco products have the lowest level of effectiveness of all 20+ countries including other LMICs [38]. Given that there exist linkages between the effectiveness of health warnings and subsequent intentions to quit $[39,40]$, and that quit intentions are a strong predictor of future quit attempts [41-43], it is clear that the low effectiveness of health warnings on tobacco products in India represents a considerable lost opportunity for reducing both consumption and prevalence of tobacco use.

The results from this study highlight the critical need to improve the salience and other downstream effects of HWLs on SLT products. To date, the progress of India's HWLs on both smoked and SLT has reflected a tangled exchange between the tobacco industry and the Indian government [22]. Research evidence on whether the effectiveness of warnings-on both smokeless and smoked tobacco products-will continue to be an important component of efforts to increase the impact of policies in this domain. Notably however, India's government has implemented new mandated warnings that are among the strongest in the world (as of April 1, 2016). These new labels now cover $85 \%$ of the front and back of the principal surfaces of the packaging [44]. The industry however has attempted to fight back by halting tobacco production. The industry is claiming that they paused manufacturing because of confusion over the new HWL requirements, but antismoking activities claim that this was in fact an attempt to put pressure on regulators through means of economic impact (e.g., through losses in employment of factory workers and farmers and tax revenues) [45]. 
The findings in this study should be interpreted with caution, mainly due to measurement and generalizability. With regard to measurement, we did not ask about a number of variables that might have contributed to the low awareness of the HWLs, including whether their SLT came in a package or container, purchasing of illicit products, or if their SLT product was home-made. Moreover, the TCP Survey was conducted in 4 states in India, and so generalization to India as a whole is not possible. Additionally, the post-policy survey for SLT quitters did not include a question that directly asked if they quit using SLT because of the HWLs, therefore no conclusions can be made about the impact of the warnings on their decision to quit.

Although there are some study limitations, this is the first population longitudinal cohort study to examine the impact of HWLs on SLT packages in India. Moreover, this study included a large number of participants, particularly women, rural inhabitants, and low education people where SLT is most prevalent.

\section{Conclusions}

Health warnings on SLT packages in India are low in effectiveness, and the change from the symbolic warning (pre-policy) to graphic HWLs (post-policy) did not lead to significant increases of effectiveness on any of the HWL indicators among those who continued to use SLT products, thus suggesting that changing an image alone is not enough to have an impact. There is a critical need to implement SLT HWLs in India that are more salient (large in size and on the front and back of the package) and impactful, which following from studies of HWLs on cigarette packaging, would have strong potential to increase awareness of the harms of SLT and to motivate quitting.

\section{Additional files}

Additional file 1: Table S1. Type of products used by SLT respondents by state among those who reported using only one product. (DOC $50 \mathrm{~kb}$ )

Additional file 2: Table S2. GEE analysis examining differences in awareness and salience of health warning labels on smokeless tobacco between pre- and post-policy periods (Waves 1 and 2) among all pre-and post-policy completers $(N=5142)$ those that quit SLT by post-policy $(n=508)$. (DOC $40 \mathrm{~kb})$

\section{Abbreviations}

GEE: Generalized estimated equations; HWL: Health warning label; SEAR: South East Asian Region; TCP: Tobacco control project; WHO FCTC: World health organization Framework Convention on Tobacco Control

\section{Acknowledgements}

The authors would like to acknowledge and thank all those that contributed to the TCP India Project: all study investigators, the project managers at University of Waterloo, Canada; the TCP India Research Team at Healis-Sekhsaria Institute for Public Health, Navi Mumbai, India, the state collaborators of the TCP India Survey and their field teams for their dedicated efforts in collecting data: Bihar-School of Preventive Oncology; West Bengal-Cancer Foundation of India; Madhya Pradesh-Madhya Pradesh Voluntary Health Association; and Maharashtra-Healis-Sekhsaria Institute for Public Health.

\section{Funding}

The TCP India Project was supported by grants from the US National Cancer Institute (P01-CA138389), Canadian Institute of Health Research (115016). Additional support was provided to GTF from a Senior Investigator Award from the Ontario Institute for Cancer Research and a Prevention Scientist Award from the Canadian Cancer Society Research Institute. SG is funded by a Canadian Cancer Society Career Development Award in Prevention.

\section{Availability of data and materials}

Data from the International Tobacco Control Policy Evaluation (ITC) Project are available to approved researchers 2 years after the date of issuance of cleaned data sets by the ITC Data Management Centre. Researchers interested in using ITC data are required to apply for approval by submitting an International Tobacco Control Data Repository (ITCDR) request application and subsequently to sign an ITCDR Data Usage Agreement. To avoid any real, potential, or perceived conflict of interest between researchers using ITC data and tobacco-related entities, no ITCDR data will be provided directly or indirectly to any researcher, institution, or consultant that is in current receipt of any grant monies or in-kind contribution from any tobacco manufacturer, distributor, or other tobacco-related entity. The criteria for data usage approval and the contents of the Data Usage Agreement are described online (http://www.itcproject.org)

\section{Authors' contributions}

SG drafted the manuscript. GTF, ACKQ, PCG and MSP all conceived the study and/or made substantial contributions to study conception and design and acquisition of data. PD conducted the statistical analyses. SX and ACKQ managed the TCP India survey project from beginning to end. All the authors contributed to interpretation of results and revision of the manuscript. All the authors read and approved the final manuscript, and agreed to be accountable for all aspects of the work in ensuring that questions related to the accuracy or integrity of any part of the work are appropriately investigated and resolved.

\section{Competing interests}

The authors declare that they have no competing interests.

\section{Consent for publication}

Not applicable.

\section{Ethics approval and consent to participate}

Ethics clearance was granted by the University of Waterloo, Office of Research Ethics (Waterloo, Canada) and the Healis-Sekhsaria Institute for Public Health Institutional Review Board (Navi Mumbai, India). All study participants provided written consent.

\section{Author details}

${ }^{1}$ Department of Psychology, University of Waterloo, 200 University Avenue West, Waterloo, ON N2L 3G1, Canada. Institute for Cancer Research, Toronto, Canada. ${ }^{3}$ School of Public Health and Health Systems, University of Waterloo, Waterloo, ON, Canada. ${ }^{4}$ Healis-Sekhsaria Institute for Public Health, Navi Mumbai, India.

Received: 30 April 2016 Accepted: 1 December 2016 Published online: 13 December 2016

\section{References}

1. World Health Organization. $90 \%$ of smokeless tobacco users live in SouthEast Asia. Available at: http://www.searo.who.int/mediacentre/releases/2013/ pr1563/en/. Accessed 11 Feb 2016.

2. National Cancer Institute and Centers for Disease Control and Prevention. Smokeless Tobacco and Public Health: A Global Perspective. Bethesda, MD: U.S. Department of Health and Human Services, Centers for Disease Control and Prevention and National Institutes of Health, National Cancer Institute. NIH Publication No. 14-7983; 2014.

3. Campaign for Tobacco Free Kids. Health harms from smokeless tobacco. Available at: http://www.tobaccofreekids.org/facts_issues/fact_sheets/toll/ products/smokeless/. Accessed 11 Apr 2016. 
4. Cullen JW, Blot W, Henningfield J, Boyd G, Mecklenburg R, Massey MM. Health consequences of using smokeless tobacco: summary of the Advisory Committee's report to the Surgeon General. Public Health Rep. 1986;101(4): 355-73.

5. Siddiqi K, Shah S, Abbas SM, Vidyasagaran A, Jawad M, Dogar O, et al. Global burden of disease due to smokeless tobacco consumption in adults: analysis of data from 113 countries. BMC Med. 2015;13:194. 015-0424-2.

6. Gupta PC, Ray CS. Smokeless tobacco and health in India and South Asia. Respirology. 2003;8(4):419-31.

7. Stepanov I, Gupta PC, Dhumal G, Yershova K, Toscano W, Hatsukami D, et al High levels of tobacco-specific N-nitrosamines and nicotine in Chaini Khaini, a product marketed as snus. Tob Control. 2015;24(e4):e271-4.

8. Stanfill SB, Connolly GN, Zhang L, Jia LT, Henningfield JE, Richter $P$, et al. Global surveillance of oral tobacco products: total nicotine, unionised nicotine and tobacco-specific N-nitrosamines. Tob Control. 2011;20(3):e2.

9. Gupta R, Gupta N, Khedar RS. Smokeless tobacco and cardiovascular disease in low and middle income countries. Indian Heart J. 2013:65(4):369-77.

10. Singh S, Mini GK, Thankappan KR. Tobacco use during pregnancy in rural Jharkhand, India. Int J Gynaecol Obstet. 2015;131(2):170-3.

11. Inamdar AS, Croucher RE, Chokhandre MK, Mashyakhy MH, Marinho VC. Maternal smokeless tobacco use in pregnancy and adverse health outcomes in newborns: a systematic review. Nicotine Tob Res. 2015;17(9):1058-66.

12. England L, Kim SY, Tomar SL, Ray CS, Gupta PC, Eissenberg T, et al. Noncigarette tobacco use among women and adverse pregnancy outcomes. Acta Obstet Gynecol Scand. 2010;89(4):454-64.

13. World Health Organization, Regional Office for South East Asia. $90 \%$ of smokeless users live in South-East Asia. 2013; Available at: http://www.searo. who.int/mediacentre/releases/2013/pr1563/en/. Accessed 25 Apr 2016.

14. Majmudar VP, Mishra AG, Kulkarni VS, Dusane RR, Shastri SS. Tobacco-related knowledge, attitudes, and practices among urban low socioeconomic women in Mumbai, India. Indian J Med Paediatr Oncol. 2015;36(1):32-7.

15. Sarkar BK, Arora M, Gupta VK, Reddy KS. Determinants of tobacco cessation behaviour among smokers and smokeless tobacco users in the states of Gujarat and Andhra Pradesh, India. Asian Pac J Cancer Prev. 2013;14(3):1931-5.

16. ITC Project (September 2. TCP India National Report. Findings from the Wave 1 Survey (2010-2011). University of Waterloo, Waterloo, Ontario, Canada; Healis-Sekhsaria Institute for Public Health, Navi Mumbai, India. Available at: http://www.google.ca/url?sa=t\&rct=j\&q=\&esrc=s\&source $=$ web\&cd=1\&ved=0CBwQFjAAahUKEwjh|4eamfLIAhUI8x4KHTm1CQ0\&url= http\%3A\%2F\%2Fwww.itcproject.org\%2Ffiles\%2FTCP IndiaNR-ENG-Sept25vweb.pdf\&usg=AFQjCNHD24GIRQOE1_ix5zo3AgJUc4tIQ\&bvm=bv.10637 9543,d.dmo. Accessed 11 Feb 2016.

17. Hammond D. Health warning messages on tobacco products: a review. Tob Control. 2011;20:327-37.

18. National Center for Chronic Disease Prevention and Health Promotion (US) Office on Smoking and Health. Preventing tobacco use among youth and young adults: A report of the Surgeon General. Atlanta (GA): Centers for Disease Control and Prevention (US); 2012.

19. Fong GT, Hammond D, Hitchman SC. The impact of graphic pictures on the effectiveness of tobacco health warnings. Bull World Health Organ. 2009;87:640-3.

20. Campaign for Tobacco Free Kids. Tobacco health warnings: evidence of effectiveness. Available at: http://www.tobaccofreekids.org/research/ factsheets/pdf/0325.pdf. Accessed 11 Apr 2016.

21. Brubaker RG, Mitby SK. Health-risk warning labels on smokeless tobacco products: are they effective? Addict Behav. 1990;15(2):115-8.

22. Arora M, Yadav A. Pictorial health warnings on tobacco products in India: sociopolitical and legal developments. Natl Med J India. 2010;23(6):357-9.

23. Ray CS, Pednekar MS, Prakash C. Gupta PC, Narake SS, Bansal-Travers M, Fong GT. Social influence on adult tobacco use, results from the TCP India survey. Tob Control: In Press.

24. Oswal KC, Pednekar MS, Gupta PC. Tobacco industry interference for pictorial warnings. Indian J Cancer. 2010;47 Suppl 1:101-4.

25. Raute LJ, Mangesh S, Pednekar MS, Gupta PC. Pictorial health warnings on cigarette packs: a population based study findings from India. Tobacco Use Insights. 2009;2:11-6.

26. WHO Framework Convention on Tobacco Control. Guidelines for implementation of Article 11 of the WHO Framework Convention on Tobacco Control on "Packaging and labelling of Tobacco Products" (decision FCTC/COP3(10)). Available at: http://www.who.int/fctc/quidelines/ article_11.pdf?ua=1. Accessed 22 Aug 2016.
27. Government of India. Ministry of Health \& Family Welfare. The Gazette of India. GSR No. 570(E) dated 26th July 2011. July, 2011; Available at: http://www.mohfw.nic.in/showfile.php?lid=895. Accessed 16 Aug 2016.

28. Campaign for Tobacco Free Kids. Country details for India: Health Warnings/ Messages Features. Available at: http://www.tobaccocontrollaws.org/ legislation/country/india/pl-health-warnings. Accessed 11 Apr 2016.

29. Arora M, Tewari A, Nazar GP, Gupta VK, Shrivastav R. Ineffective pictorial health warnings on tobacco products: lessons learnt from India. Indian J Public Health. 2012;56(1):61-4.

30. Oswal KC, Raute LJ, Pednekar MS, Gupta PC. Are current tobacco pictorial warnings in India effective? Asian Pac J Cancer Prev. 2011;12(1):121-4.

31. Karinagannanavar A, Raghavendra B, Hemagiri K, Goud TG. Awareness about pictorial warnings on tobacco products and its impact on tobacco consumers in Bellary, India. Asian Pac J Cancer Prev. 2011;12(10):2485-9.

32. International Agency for Research on Cancer (IARC). Methods for evaluating tobacco control policies. International agency for research on cancer (IARC) handbook 12 on cancer prevention, tobacco control. Lyon, France. Geneva: WHO Press; 2008.

33. ITC Project. Technical Reports. Available at: http://www.itcproject.org/ technical-report/?country=India. Accessed 25 Apr 2016

34. Pant NK, Pandey KC, Madabhavi I, Pandey V, Revannasiddaiah S. Evaluation of the knowledge and perceptions with regards to pictorial health warnings on tobacco products among tobacco users diagnosed with head and neck carcinoma: a study from the Kumaon Hills of India. Asian Pac J Cancer Prev. 2014;15(18):7891-5.

35. Agrawal SS, Ray RS. Nicotine contents in some commonly used toothpastes and toothpowders: a present scenario. J Toxicol. 2012;2012:237506.

36. Agrawal SS, Rajagopal K. Nicotine contents in various toothpowders (dant manjans): measurement and safety evaluation. Food Chem Toxicol. 2009; 47(3):511-24

37. Mutti S, Reid JL, Gupta PC, Pednekar MS, Dhumal G, Nargis N, et al. Perceived effectiveness of text and pictorial health warnings for smokeless tobacco packages in Navi Mumbai, India, and Dhaka, Bangladesh: findings from an experimental study. Tob Control. 2016;25(4):437-43.

38. ITC Project. Pictorial health warnings in India: Why Larger Warnings Should Be Implemented Without Delay. Available at: http://itcproject.org/files/India_ WL_Fact_Sheet_Draft-May26-FINAL-V2.pdf. Accessed 20 Mar 2016.

39. Borland $\mathrm{R}$, Yong $\mathrm{HH}$, Wilson $\mathrm{N}$, Fong GT, Hammond D, Cummings KM, et al. How reactions to cigarette packet health warnings influence quitting: findings from the ITC four country survey. Addiction. 2009;104(4):669-75.

40. Yong HH, Borland R, Thrasher JF, Thompson ME, Nagelhout GE, Fong GT, et al. Mediational pathways of the impact of cigarette warning labels on quit attempts in four coutries: an application of the international tobacco control (ITC) conceptual model. Health Psychol. 2014;33(11):1410-20.

41. Smit ES, Hoving C, Schelleman-Offermans K, West R, de Vries H. Predictors of successful and unsuccessful quit attempts among smokers motivated to quit. Addict Behav. 2014;39(9):1318-24.

42. Norman $\mathrm{P}$, Conner M, Bell R. The theory of planned behavior and smoking cessation. Health Psychol. 1999;18(1):89-94.

43. Wong DC, Chan SS, Fong DY, Leung AY, Lam DO, Lam TH. Patterns and predictors of quitting among youth quitline callers in Hong Kong. Nicotine Tob Res. 2011;13(1):7-14.

44. Government of India. Ministry of Health \& Family Welfare. Notification. New Delhi, October 15, 2014. Available at: http://karhfw.gov.in/nrhm/NTCP/ Letter\%20for\%20Enforcement\%20lssued\%20to\%20Chief\%20Secrtaries\%20 of\%20All\%20State\%20Governments(Annexure-A).pdf. Accessed 9 Sep 2016.

45. The Wall Street Journal. Indian Tobacco Firms Halt Cigarette Output as They Fight New Warning Labels. Available at: http://www.wsj.com/articles/indiantobacco-firms-halt-cigarette-output-as-they-fight-new-warning-labels-14605 63592. Accessed 20 Apr 2016. 